\title{
Exclusive Contracts and the Institution of Bankruptcy*
}

\author{
Alberto Bisin \\ NYU
}

\author{
Adriano A. Rampini \\ Northwestern University
}

\author{
First Version: August 1999 \\ This Version: February 2004
}

\begin{abstract}
This paper studies the institution of bankruptcy when exclusive contracts cannot be enforced ex ante, e.g., a bank cannot monitor whether the borrower enters into contracts with other creditors. The institution of bankruptcy enables the bank to enforce its claim to any funds that the borrower has above a fixed "bankruptcy protection" level. Bankruptcy improves on non-exclusive contractual relationships but is not a perfect substitute for exclusivity ex ante. We characterize the effect of bankruptcy provisions on the equilibrium contracts which borrowers use to raise financing.
\end{abstract}

JEL: D82, G33, K29. Keywords: Bankruptcy, non-exclusive contracts.

\footnotetext{
${ }^{*}$ We thank the seminar participants at Carnegie Mellon, Columbia, Illinois, Minnesota, Northwestern, Pompeu Fabra, Stanford, the CEPR European Summer Symposium in Financial Markets, the NBER Corporate Finance Program Meeting, the SED Annual Meeting, the Texas Finance Festival, the WFA Annual Conference, the Workshop on Information, Financial Markets and the Business Cycle in Rome and the Federal Reserve Bank of Richmond and in particular Marco Bassetto, Alberto Bennardo, Philip Bond, Peter DeMarzo, Andrea Eisfeldt, Michael Fishman, Zsuzsanna Fluck, Denis Gromb, Oliver Hart, Eugene Kandel, John Kareken, Stephan Krasa, Arvind Krishnamurthy, Deborah Lucas, Thomas Noe, Onur Ozgur, Mitchell Petersen, Artur Raviv, Jeffrey Zwiebel, and especially Narayana Kocherlakota for helpful comments, and Nisan Langberg for research assistance. Bisin gratefully acknowledges the research support of the National Science Foundation under Grant No. SES-9818844 and the C.V. Starr Center for Applied Economics. Address: Bisin: Department of Economics, New York University, 269 Mercer Street, New York, NY, 10003. Email: alberto.bisin@nyu.edu. Rampini (Corresponding Author): Department of Finance, Kellogg School of Management, Northwestern University, 2001 Sheridan Road, Evanston, IL, 60208. Email: rampini@northwestern.edu. Phone: (847) 467-1841. Fax: (847) 491-5719.
} 


\section{Introduction}

This paper studies the role of bankruptcy in an environment in which borrowers can enter into multiple credit relationships which are not observed by all parties, i.e., in which contracts are non-exclusive. Specifically, we consider the problem of a bank which can not ex ante write contracts contingent on the total assets and liabilities of a borrower, since subsequent contractual relationships are not observed by the bank. The inability to enforce exclusivity ex ante constrains the contracts that the borrower is able to obtain. In our model, the institution of bankruptcy enables the bank to enforce its claim to any funds exceeding a fixed amount, the "bankruptcy protection" level. It allows the bank to ensure that the borrower keeps no more than that fixed amount. Bankruptcy hence alleviates the non-exclusivity problem and is valuable.

We explicitly model the inability to make contracts contingent on subsequent contractual relationships by assuming that such relationships are unobservable. ${ }^{1}$ Our focus is on the role which bankruptcy plays in limiting the externalities across contracts and on the effect of bankruptcy provisions on the equilibrium contracts which borrowers and lenders enter into ex ante. ${ }^{2}$ In contrast, much of the existing literature focuses on the role of bankruptcy in conflict resolution amongst creditors ex post, i.e., after insolvency. ${ }^{3,4}$

We study the problem of a borrower or entrepreneur who needs to raise financing from a primary lender, which we call the "bank," and who can raise additional funds from secondary lenders. ${ }^{5}$ The borrower is subject to moral hazard and needs

\footnotetext{
${ }^{1}$ See Arnott and Stiglitz (1983) for a pioneering analysis in economies with hidden action and, more recently, Bisin and Guaitoli (1998), Bizer and DeMarzo (1992, 1999) and Kahn and Mookherjee (1998). Allen (1985), Fudenberg, Holmström, and Milgrom (1990), and Cole and Kocherlakota (2001) study related environments with different forms of non-exclusivity, namely hidden borrowing and lending and hidden storage, respectively. A related literature discusses the opportunistic access to secondary markets in the case of equity (see Admati, Pfleiderer and Zechner (1994) and references therein).

${ }^{2}$ See Dubey, Geanakoplos, and Shubik (2003) and Zame (1993) for a general equilibrium analysis of contracts with default provisions and Schwartz (1997) for an analysis of the distinction between contracts with default provisions and bankruptcy institutions.

${ }^{3}$ See, e.g., Aghion, Hart, and Moore (1992), Bebchuk (1988), and Cornelli and Felli (1998) for models which focus on the division of the debtor's assets among lenders in the event of insolvency. Models which study the effect of bankruptcy on contracting ex ante include Berglöf, Roland, and von Thadden (2003) who study the effect on the equilibrium capital structure of firms and Berkovitch, Israel, and Zender (1997) who study the effect on firm specific investment.

${ }^{4}$ We underplay the classical argument for bankruptcy institutions, namely that they avoid uncoordinated actions by creditors affecting the debtor's assets in case of his inability to repay (see, e.g., Baird (1993)), in order to highlight the most novel components of our analysis.

${ }^{5}$ See Berglöf and von Thadden (1994), Biais and Gollier (1997), Bolton and Scharfstein (1996), Dewatripont and Maskin (1995), Dewatripont and Tirole (1994), and Winton (1995) for models of multiple lending relationships in equilibrium. For evidence on multiple contractual
} 
to be given incentives to exert effort.

The institution of bankruptcy in our set-up has two essential elements: First, it enables the bank to enforce its claim to any assets that the borrower has above a fixed bankruptcy protection level. In particular, the bank can seize payoffs of secondary contracts which the borrower would be due to receive. The bank can thus enforce a specific consumption allocation for the borrower in bankruptcy. A necessary condition for this is that the payments which the borrower makes or receives are observable in bankruptcy. Second, it provides a level of bankruptcy protection to the borrower in the form of a guaranteed payoff for the entrepreneur.

We first characterize the effects of non-exclusivity of contracts due to the inability to write contracts contingent on the total assets and liabilities of a borrower in a benchmark economy without this bankruptcy institution. We show that the inability to enforce exclusivity clauses has two effects on the optimal contract compared to exclusive contracts. First, it reduces the insurance provided by the repayment schedule of the bank's loan against the possibility that the project fails. Second, it reduces the amount that the entrepreneur can borrow. By reducing the amount of insurance, the bank leaves the borrower with more resources in states where the project is successful. With low effort such resources have lower expected value and are hence less valuable. This makes it more costly for the borrower to deviate to low effort and trade with secondary lenders.

We then introduce the bankruptcy institution into this environment where exclusive contracts are not otherwise enforceable. In this case, the bank chooses a repayment schedule which induces the entrepreneur to declare bankruptcy if and only if the project fails. Since the bank can seize any additional assets that the borrower might have if these exceed the bankruptcy protection level, the borrower has no incentive to acquire such assets ex ante. Indeed, the borrower is not tempted to save in secondary markets, but, if anything, would consider taking out additional loans. This is in contrast to the counterintuitive result in the standard principal agent analysis of credit relationships (see, e.g., Rogerson (1985)) that the borrower is tempted to save in secondary markets. ${ }^{6}$

Furthermore, the bank can ensure that secondary lenders are repaid only if the bank has been repaid in full, which means that debt in secondary markets will not be repaid when the project fails. Hence, the entrepreneur can not borrow from secondary lenders against the state in which he declares bankruptcy. Bankruptcy thus restricts the set of contracts that the entrepreneur can enter into in the secondary market.

If the bankruptcy protection level is chosen appropriately, the institution of bankruptcy alleviates the incentive problem resulting from the non-exclusivity of

relationships see, e.g., Petersen and Rajan (1997).

${ }^{6}$ See however Bizer and DeMarzo (1999) for an important exception. 
contracts and is welfare improving. Furthermore, the optimal contract offered by the bank provides the entrepreneur with more insurance and a larger loan than is provided under the optimal contract in the absence of bankruptcy.

The bankruptcy institution in our model provides a level of bankruptcy protection to the borrower and hence limits the liability of the borrower. This level of bankruptcy protection is a crucial and endogenous element of the institution of bankruptcy rather than an exogenous friction. Thus, being generous to the insider is optimal in our model. In practice, provisions in the corporate bankruptcy code which are lenient to the insiders, namely Chapter 11, effectively provide some bankruptcy protection to insiders. ${ }^{7}$ Under Chapter 11 the debtor is allowed to restructure after disclosing the books to the court and possibly proceed with the project. Similarly, the frequent attribution of control rights to the insiders as well as the extensively documented deviations from absolute priority in favor of insiders (see, e.g., Franks and Torous (1989)) $)^{8}$ provide implicit bankruptcy protection. ${ }^{9}$ Moreover, for individual bankruptcy, which is often applied to bankruptcies of entrepreneurial firms, the U.S. Code explicitly specifies insurance provisions, in the form of the fresh start policy for individual debtors. ${ }^{10}$ Our model suggests that this generosity towards insiders is beneficial because borrowers need to be induced to declare bankruptcy since bankruptcy enables the bank to enforce its claim. This is valuable for contracting ex ante. In contrast, the literature which studies the role of bankruptcy in resolving conflicts between creditors ex post focuses on the costs of generosity and questions the role of restructuring procedures which are generous to insiders. ${ }^{11}$

We then show that the institution of bankruptcy is not a perfect substitute for the enforceability of exclusive contracts, however. Bankruptcy restricts the set of contracts offered to the entrepreneur in the secondary market considerably. This reduces the ex ante non-exclusivity problem and is valuable. But it is not equiv-

\footnotetext{
${ }^{7}$ See Baird (1993) for an introduction to the bankruptcy code and Berkovitch and Israel (1999) for a comparative analysis of bankruptcy laws.

${ }^{8}$ Notice that the focus here is on violations of absolute priority between insiders and outsiders rather then between lenders with different seniority.

${ }^{9}$ This interpretation is admittedly loose, since we do not model restructuring procedures explicitly. For the case of individual bankruptcy however, Baird (1993), for instance, stresses that one of the main purposes of the Code is that it "allows creditors to scrutinize the debtor's affairs and, assuming no misbehavior is found, it provides the debtor with a fresh start" (p. 32).

${ }^{10}$ Liquidation procedures, as in Chapter 7 of the U.S. Code, are seen mainly as a device which limits the diversion of assets away from senior claimants. Consistently Baird (1993) argues that "[t]he purpose of allowing corporations to file Chapter 7 petitions is not so much to give creditors assets, as it is to assure creditors that the corporation has no assets" (p. 15). See also Schwartz (1989).

${ }^{11}$ Aghion, Hart, and Moore's bankruptcy reform, for instance, calls for a variant of the liquidation procedure contained in Chapter 7 and the abandonment of the restructuring procedures of Chapter 11 (see also Hart et al. (1997)).
} 
alent to being able to enforce a specific consumption allocation for the borrower in all states. The repayment schedule offered by the bank must still be such that the entrepreneur has no incentive to choose any secondary contracts. ${ }^{12}$

We believe that the environment we analyze captures an important element of credit markets. The secondary credit market for instance does not have to be interpreted literally as borrowing from a second bank, although this is a possible interpretation. Trade credit, which is an important source of financing for firms in the United States (see, e.g., Petersen and Rajan (1997)), can also be a secondary source of funds. So can other providers of working capital through accounts payable, such as employees or the tax authority. The secondary source may also be credit card financing in addition to a primary bank loan (in particular for small firms) or unsecured, informal lending supplementing a first, formal loan. Also, the focus of the paper is on unsecured lending, i.e., loans that are not collateralized by specific assets, which is an important source of financing especially for small firms. ${ }^{13}$

The paper proceeds as follows. Section 2 describes the model. Section 3 characterizes and compares the optimal contracts in three environments. In Section 3.1 we characterize the optimal exclusive contract, i.e., the optimal contract with neither a secondary credit market nor bankruptcy. In Section 3.2 we study non-exclusive credit relationships when there is no bankruptcy institution. In Section 3.3 we consider the effect of the institution of bankruptcy when credit relationships are non-exclusive. Section 4 provides a discussion of some of the assumptions, implications, and possible extensions. Section 5 concludes.

\section{The Model}

We study an economy in which an entrepreneur needs to borrow to finance a project. The probability of success of the project depends on a costly unobservable action by the entrepreneur. A bank financing the project schedules repayments, conditional on the outcome of the project, such that the entrepreneur has an incentive to take the action which maximizes the value of the project. We consider and compare three cases: i) The bank is the only lender, and the entrepreneur cannot declare bankruptcy. ii) The entrepreneur can raise funds in addition to those obtained from the bank from "secondary lenders." The bank cannot condition the repayment schedule of the loan on the total funds raised by the entrepreneur, because the bank does not observe subsequent contractual re-

\footnotetext{
${ }^{12}$ This result contrasts with the result derived by Bizer and DeMarzo (1999) in an interesting related paper which is discussed in more detail in Section 4.

${ }^{13}$ The fraction of loans to firms with less than 500 employees which are not collateralized is $31 \%$ in data from the 1993 National Survey of Small Business Finances.
} 
lationships of the entrepreneur, and the entrepreneur cannot declare bankruptcy. iii) The entrepreneur can raise funds in addition to those obtained from the bank. The bank cannot condition the repayment schedule of the loan on the total funds raised by the entrepreneur, but the entrepreneur can declare bankruptcy. If he does declare bankruptcy, the bank can ensure that the borrower does not keep any funds exceeding a fixed amount (the level of "bankruptcy protection"), and the entrepreneur consumes a fixed, predetermined amount. In other words, the institution of bankruptcy in our model has two essential components: First, it enables the bank to seize any funds that the borrower has in excess of the bankruptcy protection level up to the amount of its loan if bankruptcy is declared. Second, it provides a level of bankruptcy protection to the borrower in the form of a guaranteed allocation for the entrepreneur. Thus, we assume that in bankruptcy the enforcement of the seniority of the bank's claim with respect to the entrepreneur's claim is limited by the bankruptcy protection level.

\subsection{The Economy}

We consider a simple economy with two dates 0 and 1 , and one single consumption good that is populated by an entrepreneur and several agents which operate in credit markets. We will distinguish between an agent which will take the role of the main creditor of the entrepreneur, which, for concreteness, we call the bank, and all the other potential creditors which populate what we call the secondary credit market.

The Entrepreneur. The entrepreneur is endowed with $\alpha<1$ units of the good at time 0 and has the opportunity to start a project, which requires an investment of 1 unit of the consumption good at time 0 . At time 1 , the project yields $\omega_{H}$ units of the consumption good with probability $\pi_{a}$ and $\omega_{L}$ units of the consumption good with probability $1-\pi_{a}$. a denotes an unobservable action by the entrepreneur, effort toward the success of the project, which affects the probability distribution of the outcome of the project, and takes two values, $e$ and $E$. Without loss of generality, $\omega_{H}>\omega_{L}$ and $\pi_{E}>\pi_{e}$, so that $\omega_{H}$ takes the interpretation of 'high' realization of the output of the project and $E$ of 'high' effort.

The entrepreneur has preferences represented by a continuous, smooth, strictly monotonic increasing, strictly concave Von Neumann-Morgenstern utility function, $u: \mathbb{R}_{+} \rightarrow \mathbb{R}$. Denoting consumption at time 0 and 1 with $c_{0}$ and $c_{1}$, respectively, the entrepreneur's lifetime utility is

$$
U=u\left(c_{0}\right)+\mathrm{E}\left[u\left(c_{1}\right) \mid a\right]-v(a),
$$

where $\mathrm{E}[\cdot \mid a]$ denotes the expectation conditional on action $a$. This specification of preferences assumes separability of consumption and effort and no discounting for 
tractability. Consistent with the interpretation of $E$ as 'high' effort, we assume $v(E)>v(e)$.

The entrepreneur finances his project in the credit markets. All agents in the credit markets are identical, risk neutral and ready to invest in the entrepreneur's project, i.e., there is free entry. The first agent the entrepreneur enters into a contractual relationship with will have the special role of the primary creditor and will be called the bank.

The Bank. At time 0, the bank provides the entrepreneur with funds $I \in \mathbb{R}$ (possibly negative) to operate the project and/or smooth consumption. It sets state contingent repayments for time $1,\left(B_{H}, B_{L}\right)$, to maximize expected profits. ${ }^{14}$ Expected profits are evaluated at the entrepreneur's equilibrium action $a \in\{e, E\}$, and at the equilibrium repayment levels $\left(\tilde{B}_{H}, \tilde{B}_{L}\right)$ in case the entrepreneur decides not to fully repay his debt. Since we assume no discounting, we set the exogenous interest rate to 0 , and the bank's expected profits are:

$$
\pi_{a} \tilde{B}_{H}+\left(1-\pi_{a}\right) \tilde{B}_{L}-I
$$

The entrepreneur, after entering the contractual relationship with the bank, might trade with secondary lenders in the secondary credit market.

The Secondary Lenders. Any secondary lender observes $I, B_{H}, B_{L}$, and then potentially provides the entrepreneur at time 0 with extra credit, $\gamma \in \mathbb{R}$ (possibly negative), and a state contingent repayment scheme at time $1,\left(R_{H}, R_{L}\right)$, also to maximize expected profits evaluated at the entrepreneur's equilibrium action $a \in\{e, E\}$, and equilibrium repayment levels $\left(\tilde{R}_{H}, \tilde{R}_{L}\right): \pi_{a} \tilde{R}_{H}+(1-$ $\left.\pi_{a}\right) \tilde{R}_{L}-\gamma$.

The Bankruptcy Institution. The entrepreneur might decide not to repay his debt with the bank and/or with the secondary lenders. In this case, i) the bank can ensure that the entrepreneur can not keep any funds exceeding a fixed amount, the bankruptcy protection level $P$, and $i$ ) the entrepreneur receives a fixed amount of $P$ units of consumption. Specifically, the bank receives the difference between the output of the project plus any positive payoffs of other claims the entrepreneur might have and $P$, up to the full credit amount. The bank hence enforces the seniority of its loan which is however limited by the bankruptcy protection level of the borrower. Secondary lenders are partially reimbursed if and only if the bank is fully repaid. ${ }^{15}$ We assume that the secondary lenders get equal shares of the proceeds in bankruptcy, up to the amount of their loan. As we discuss in Section 4,

\footnotetext{
${ }^{14}$ We assume that the bank can commit to the contract it offers, including the repayment schedule, at time 0 . See Park (2003) for the case in which the bank can renegotiate at time 1 after the effort choice of the entrepreneur but before the outcome of the project.

${ }^{15}$ If the output of the project is sufficient to repay all of the entrepreneur's debt after guaranteeing himself at least $P$, there is no reason for him not to repay and declare bankruptcy. Notice that, out of equilibrium, if bankruptcy is declared when there are enough resources to
} 
this specific assumption about the sharing rule in bankruptcy is not critical for our main conclusion. It simplifies the characterization of the solution by allowing us to essentially ignore the strategic interaction in the secondary market and proceed as if there were only one secondary lender. Notice that in bankruptcy the bank can only enforce its claim to any funds exceeding the bankruptcy protection level that the borrower has, and can not impose more general penalties on either secondary lenders or the borrower even if the borrower has violated the exclusivity covenants.

Courts. While we do not model courts explicitly as an agent in the economy, it is important to stress that our bankruptcy institution can be implemented by courts as follows. The contract between the bank and the entrepreneur is deposited in court, or in a credit bureau operated by the courts, and therefore registered and dated. Whenever bankruptcy is called, the courts verify the state of insolvency of the entrepreneur and enforce the bank's claim on funds exceeding the bankruptcy protection level. All private contracts put forward to the courts in the state of insolvency, even those not registered in the credit bureau, are honored by the bankruptcy process. The bank can (and will, without loss of generality) register its contract and impose an exclusivity covenant, therefore eliminating any possible seniority structure between potential secondary lenders, which then have no incentive to deposit their contracts with the credit bureau. This justifies our assumption that secondary lenders are repaid equal shares of what is left after reimbursing the bank holding what is effectively a senior claim and providing the entrepreneur with $P$ units of consumption.

\subsection{Assumptions}

We impose the following assumptions.

Assumption 1 Preferences satisfy $\lim _{c \rightarrow 0} u^{\prime}(c)=\infty, \lim _{c \rightarrow 0} u(c)=-\infty$ and are extended to the entire real line with $u(c)=-\infty$ for $c<0$.

This assumption guarantees positivity of consumption in equilibrium. Furthermore, the assumption formally guarantees that the agent never wants to enter into inconsistent contracts that result in negative consumption.

Assumption 2 Lower bound on the expected rate of return of the project:

$$
\pi_{e} \omega_{H}+\left(1-\pi_{e}\right) \omega_{L}>1
$$

The expected rate of return implied by the project, when operated at the low effort $e$, is $\pi_{e} \omega_{H}+\left(1-\pi_{e}\right) \omega_{L}$, while the safe rate of return of the economy is 1 .

repay all lenders, we assume that the entrepreneur would still receive a consumption of $P$ only, and hence resources would be wasted. 
Assumption 2 requires production efficiency of the project at effort $e$. Alternatively, the assumption requires that an agent would find it profitable to invest in the project, operate it at the low effort $e$, fully insure the outcome of the project at fair prices, and perfectly smooth his consumption at the safe rate of return 1 , rather than not operating the project and smoothing his consumption, which is deterministic if the project is not operated.

Let $c_{e} \equiv \frac{1}{2}\left(\alpha-1+\pi_{e} \omega_{H}+\left(1-\pi_{e}\right) \omega_{L}\right)$ be the consumption allocation at each date and state of the world of an agent choosing $a=e$ in the case of perfect smoothing and full insurance.

Assumption 3 Lower bound on the relative productivity of high effort E:

$$
\pi_{E} u\left(\omega_{H}-I_{e}\right)+\left(1-\pi_{E}\right) u\left(\omega_{L}-I_{e}\right)-v(E)>u\left(c_{e}\right)-v(e)
$$

where $I_{e}$ is the level of borrowing or lending which supports consumption $c_{e}$ at $t=0$, i.e., $I_{e} \equiv c_{e}-(\alpha-1)$.

Assumption 3 requires that, when consuming $c_{e}$ at time 0 , the agent would prefer to operate the project at the high effort $E$ without insurance rather than operating the project at the low effort $e$ and fully insuring the outcome of the project.

Finally, we will also assume that preferences and the parameters of the economy are such that the bank's non-negative expected profit condition holds with equality. This is always the case when contracts are exclusive, but is not a forgone conclusion when contracts are non-exclusive (see Section 3.2 and 3.3). A simple

sufficient condition is, for example, that preferences satisfy $u(c)=\frac{c^{1-\sigma}}{1-\sigma}$ with $\sigma<1$ or $u(c)=\ln (c)$.

\section{Equilibrium Contracts}

In equilibrium, the entrepreneur chooses the agent with which he enters into a primary contractual relationship, i.e., the bank he deals with. Moreover, the entrepreneur trades in the secondary credit market, thereby choosing the secondary lenders he deals with. Given the aggregate contractual position he has entered into, and given the bankruptcy institution, the entrepreneur chooses the effort he exerts toward the success of the project and a bankruptcy declaration and repayment strategy contingent on the state of the world (i.e., the outcome of the project). The bank chooses which contract to offer, anticipating the entrepreneur's trades in the secondary credit market, and anticipating the effort and bankruptcy declaration and repayment decisions of the entrepreneur. The secondary lenders choose which contracts to offer, knowing the terms of the contract between the entrepreneur and the bank, and anticipating the effort and bankruptcy declaration and repayment decisions of the entrepreneur. 
We do not explicitely describe the mechanism by which the entrepreneur chooses the agent which acts as the bank, or the agents to deal with in the secondary credit market. We instead postulate free entry in both the primary and the secondary credit markets, and hence will characterize contracts which maximize the entrepreneur's expected utility provided these contracts satisfy the non-negative expected profit condition for the bank and the secondary lenders. This is just for simplicity. A simple mechanism which supports free entry can easily be constructed. ${ }^{16}$

Before studying the equilibrium in our economy with unobservable effort, secondary lenders, and bankruptcy, we analyze the equilibrium of an economy in which exclusive contracts can be enforced as a benchmark. ${ }^{17}$

\subsection{Exclusive Contracts and No Bankruptcy}

In this subsection, we consider the case in which banks have the ability to impose exclusivity clauses on the entrepreneurs (perhaps because they can observe their trades), and thus secondary lenders do not operate. We also assume that there is no bankruptcy institution in the economy and agents are required to keep their promises. Indeed, since with exclusive contracts the bank knows exactly how many funds the agent has in each state of the world and hence how much he consumes, a bankruptcy institution as described above would not add any value here. This will of course change once we consider non-exclusive contracts.

The environment with exclusive contracts is in fact the standard principal agent model of borrowing and lending which we use as a benchmark (see Rogerson (1985)). Because we assume that many agents can act as banks (free entry), in equilibrium the bank will choose to offer the entrepreneur a contract which maximizes the entrepreneur's utility, provided the contract satisfies the bank's non-negative expected profit condition.

Assumptions 1-3 imply that an optimal contract is characterized by $a=E$ and $\alpha+I>1$. To induce effort $E$, the contract must satisfy an incentive constraint. The optimal contract offered by the bank is the solution to the following maximization problem:

$$
\max _{I, B_{H}, B_{L}} u(\alpha+I-1)+\pi_{E} u\left(\omega_{H}-B_{H}\right)+\left(1-\pi_{E}\right) u\left(\omega_{L}-B_{L}\right)-v(E)
$$

\footnotetext{
${ }^{16}$ For instance, the following mechanism would do: Agents have the option to offer a primary credit contract to the entrepreneur in an exogenous order. The entrepreneur, accepting one such contract, stops the sequence of offers. The secondary market, in which agents make offers simultaneously, then opens, and the entrepreneur accepts as many offers as he pleases.

${ }^{17}$ Under full information (observable effort) the optimal contract is characterized by high effort $(a=E)$, perfect smoothing $\left(c_{0}=\pi_{E} c_{H}+\left(1-\pi_{E}\right) c_{L}\right)$ and full insurance $\left(c_{H}=c_{L}\right)$, i.e., $c_{0}=c_{H}=c_{L}=\frac{1}{2}\left(\alpha-1+\pi_{E} \omega_{H}+\left(1-\pi_{E}\right) \omega_{L}\right)$.
} 
subject to

$$
\begin{gathered}
\pi_{E} B_{H}+\left(1-\pi_{E}\right) B_{L} \geq I \\
u(\alpha+I-1)+\pi_{E} u\left(\omega_{H}-B_{H}\right)+\left(1-\pi_{E}\right) u\left(\omega_{L}-B_{L}\right)-v(E) \geq \\
u(\alpha+I-1)+\pi_{e} u\left(\omega_{H}-B_{H}\right)+\left(1-\pi_{e}\right) u\left(\omega_{L}-B_{L}\right)-v(e) .
\end{gathered}
$$

The optimal contract maximizes the utility of the entrepreneur (1), subject to the non-negative expected profit condition of the bank (2), and the incentive compatibility constraint (3). Let $\left(I^{*}, B_{H}^{*}, B_{L}^{*}\right)$ denote the optimal contract offered by the bank. Similarly, let $\left(c_{0}^{*}, c_{H}^{*}, c_{L}^{*}\right)$ denote the equilibrium allocation of the entrepreneur (i.e., his consumption at the optimal contract).

The following proposition characterizes the consumption allocation of the entrepreneur at the optimal contract (see Rogerson (1985)).

Proposition 1 Suppose Assumptions 1-3 hold, contractual relationships are exclusive, and there is no bankruptcy institution. Then,

$$
c_{H}^{*} \equiv \omega_{H}-B_{H}^{*}>c_{L}^{*} \equiv \omega_{L}-B_{L}^{*} \quad \text { (partial insurance) },
$$

and

$$
u^{\prime}\left(c_{0}^{*}\right)<\pi_{E} u^{\prime}\left(c_{H}^{*}\right)+\left(1-\pi_{E}\right) u^{\prime}\left(c_{L}^{*}\right) \quad \text { (imperfect smoothing). }
$$

Moreover, if $1 / u^{\prime}$ is convex, then

$$
c_{0}^{*}=\alpha+I^{*}-1>\pi_{E} c_{H}^{*}+\left(1-\pi_{E}\right) c_{L}^{*} .
$$

If $1 / u^{\prime}$ is concave, the last inequality is reversed. ${ }^{18}$

All proofs are in the Appendix unless noted otherwise. Notice that imperfect smoothing is (constrained) optimal independent of the precautionary savings effect driven by the curvature of marginal utility: In fact, with linear marginal utility (quadratic preferences) savings are restricted in equilibrium, and $c_{0}^{*}=\alpha+I^{*}-1>$ $\pi_{E} c_{H}^{*}+\left(1-\pi_{E}\right) c_{L}^{*}$.

\subsection{Non-exclusive Contracts and No Bankruptcy}

We now consider the case in which contractual relationships in the credit market are non-exclusive: Secondary lenders, as well as a bank, can provide the entrepreneur with credit. The bank cannot condition the terms of its contract on the entrepreneur's trades in the secondary credit market because these trades cannot be observed. For the moment, though, we assume that there is no institution

\footnotetext{
${ }^{18}$ The borderline case is thus logarithmic utility $\left(1 / u^{\prime}\right.$ linear) for which consumption is a martingale: $c_{0}^{*}=\pi_{E} c_{H}^{*}+\left(1-\pi_{E}\right) c_{L}^{*}$.
} 
of bankruptcy. That is, the entrepreneur can not default on his debt obligations and declare bankruptcy, thereby allowing the bank to ensure that he has no additional funds from trades in secondary markets. The effect of such an institution on contracting will be considered in the next subsection.

The determination of the equilibrium contractual relationships between the bank, the entrepreneur, and the secondary lenders, as well as the equilibrium allocation of the entrepreneur, is not straightforward. However, as in the case discussed in the previous subsection, the equilibrium allocation of the entrepreneur can be uniquely determined by the solution to a programming problem. We construct such a problem below.

Note that the bank and any of the secondary lenders are identical in terms of objectives (they are risk neutral and maximize expected profits) and in terms of contract space. This implies that any agent can act as the bank, and free entry ensures that the contract offered by the bank involves zero expected profits in equilibrium (after the entrepreneur's trading with secondary lenders) given our assumptions. Furthermore, any allocation for the entrepreneur can be supported by a single contract with the bank, and no relationship with any of the secondary lenders. In other words, the set of contracts that the secondary creditors could offer the entrepreneur can also be offered by the bank ex ante. ${ }^{19}$

The equilibrium allocation for the entrepreneur can then be supported as an optimal contract restricted to one in which secondary lenders are inactive, i.e., $\gamma=R_{H}=R_{L}=0$, provided the entrepreneur does not have any incentive to choose a joint deviation of supplying effort $e$ and supplementing the bank's credit with secondary credit (an incentive compatibility constraint). In other words, the contract offered by the bank in equilibrium will be such that the entrepreneur has no reason to enter into a contract with one or several secondary lenders in order to create a portfolio which induces him to exert low effort, thereby reducing the expected repayment to the bank.

Finally, in the secondary market for credit, again because of free entry, the entrepreneur is able to obtain a contract which maximizes his utility given the contract offered by the bank provided each secondary lender makes zero expected profits in equilibrium. (Note that this is essentially independent of the specific strategic interactions between secondary lenders in the market.)

Since Assumptions 1-3 imply that the optimal contract is characterized by $a=E$ and $\alpha+I>1$, the optimal contract with secondary lenders and no bankruptcy is the solution to the following maximization problem:

$$
\max _{I, B_{H}, B_{L}} u(\alpha+I-1)+\pi_{E} u\left(\omega_{H}-B_{H}\right)+\left(1-\pi_{E}\right) u\left(\omega_{L}-B_{L}\right)-v(E)
$$

\footnotetext{
${ }^{19}$ There is thus no intrinsic role for financing by the secondary lenders in our model. It would be an interesting extension to study an environment in which secondary financing would play a non-degenerate role.
} 
subject to

$$
\begin{gathered}
\pi_{E} B_{H}+\left(1-\pi_{E}\right) B_{L} \geq I \\
u(\alpha+I-1)+\pi_{E} u\left(\omega_{H}-B_{H}\right)+\left(1-\pi_{E}\right) u\left(\omega_{L}-B_{L}\right)-v(E) \geq \\
u(\alpha+I+\gamma-1)+\pi_{e} u\left(\omega_{H}-B_{H}-R_{H}\right)+\left(1-\pi_{e}\right) u\left(\omega_{L}-B_{L}-R_{L}\right)-v(e)
\end{gathered}
$$

for all $\left(\gamma, R_{H}, R_{L}\right)$ which satisfy

$$
\pi_{e} R_{H}+\left(1-\pi_{e}\right) R_{L} \geq \gamma .
$$

The optimal contract maximizes the expected utility of the entrepreneur (4), subject to the non-negative expected profit condition of the bank (5), and the incentive compatibility constraint (6). In specifying the incentive compatibility constraint (6), we restrict the set of contracts offered in the secondary market to those which satisfy (7), i.e., non-negative expected profits for the secondary lenders. Lemma 1 shows that we can further simplify the incentive compatibility constraint (6), since the borrower will choose to fully insure using the secondary markets when he chooses low effort. Moreover, Lemma 1 shows that the incentive constraint when the borrower has access to the secondary credit market, (6), is more restrictive than when he does not, (3), since by trading in this market the entrepreneur can optimally tailor his consumption to the case in which he chooses the low effort $e$. This also implies that the borrower is better off when exclusive contracts are enforceable than when they are not.

Lemma 1 (i) Constraint (6) can be replaced by

$$
u(\alpha+I-1)+\pi_{E} u\left(\omega_{H}-B_{H}\right)+\left(1-\pi_{E}\right) u\left(\omega_{L}-B_{L}\right)-v(E) \geq 2 u(c)-v(e)
$$

where

$$
c \equiv \frac{1}{2}\left(\alpha+I-1+\pi_{e}\left(\omega_{H}-B_{H}\right)+\left(1-\pi_{e}\right)\left(\omega_{L}-B_{L}\right)\right) .
$$

(ii) Constraint (6) is more restrictive than (3).

Notice that the value to the entrepreneur of a joint deviation to effort $e$ and to secondary credit increases with the present value of wealth after the bank loan has been received, $\alpha+I-1+\pi_{e}\left(\omega_{H}-B_{H}\right)+\left(1-\pi_{e}\right)\left(\omega_{L}-B_{L}\right)$, or, using the bank's non-negative expected profit condition at equality, with $\alpha-1+\pi_{e} \omega_{H}+$ $\left(1-\pi_{e}\right) \omega_{L}+\left(\pi_{E}-\pi_{e}\right)\left(B_{H}-B_{L}\right)$, and hence it increases with $\left(B_{H}-B_{L}\right)$. To keep the borrower from trading with secondary lenders, the bank has to make it costly for the borrower to do so. By reducing the difference between $B_{H}$ and $B_{L}$, i.e., by reducing the amount of insurance provided, the bank makes the borrower's budget given low effort tighter, which makes it more costly for the borrower to deviate. 
Indeed, this intuition is reflected in the properties of the optimal non-exclusive contract discussed below.

Importantly, note that in our economy with hidden effort, the possibility of entering into additional contracts can distort the ex ante effort choice and hence the probability with which the specified repayments to the bank are being made. If the borrower were to exert low effort, the expected repayment would be reduced even if the borrower were to make the specified repayments to the bank. Hence, the allocation is bounded away from the optimal allocation with exclusivity.

Let $\left(c_{0}^{* *}, c_{H}^{* *}, c_{L}^{* *}\right)$ denote the equilibrium allocations of the debtor (i.e., his consumption at the optimal contract). Similarly, let $\left(I^{* *}, B_{H}^{* *}, B_{L}^{* *}\right)$ denote the optimal contract offered by the bank.

Proposition 2 Suppose Assumptions 1-3 hold, contractual relationships are nonexclusive, and there is no bankruptcy institution. Then

$$
c_{H}^{* *} \equiv \omega_{H}-B_{H}^{* *}>c_{L}^{* *} \equiv \omega_{L}-B_{L}^{* *} \quad(\text { partial insurance }),
$$

and

$$
u^{\prime}\left(c_{0}^{* *}\right)=\pi_{E} u^{\prime}\left(c_{H}^{* *}\right)+\left(1-\pi_{E}\right) u^{\prime}\left(c_{L}^{* *}\right) \quad \text { (perfect smoothing). }
$$

Moreover, if $u^{\prime}$ is convex, then

$$
c_{0}^{* *} \equiv \alpha+I^{* *}-1<\pi_{E} c_{H}^{* *}+\left(1-\pi_{E}\right) c_{L}^{* *} .
$$

If $u^{\prime}$ is concave, the last inequality is reversed. ${ }^{20}$

Note that the incentive constraint with a secondary credit market implies that the bank cannot use imperfect smoothing to relax the incentive problem. (In fact, with quadratic preferences, and hence no precautionary savings motive, $c_{0}^{* *}=$ $\alpha+I^{* *}-1=\pi_{E} c_{H}^{* *}+\left(1-\pi_{E}\right) c_{L}^{* *}$.) Thus, inducing the high effort $E$ is more difficult which is an additional reason why the amount of insurance that can be offered to the entrepreneur at the optimal contract is reduced by non-exclusivity.

We now compare the allocation at the optimal contract with and without a secondary credit market to confirm the intuition provided above. The main result of this section is that in general non-exclusivity of contractual relationships has the effect of reducing both the amount of borrowing and the insurance the bank can provide to the entrepreneur. More precisely,

Proposition 3 Suppose Assumptions 1-3 hold, and there is no bankruptcy institution. Then:

\footnotetext{
${ }^{20}$ The borderline case is thus quadratic utility ( $u^{\prime}$ linear) for which consumption is a martingale: $c_{0}^{* *}=\alpha+I^{* *}-1=\pi_{E} c_{H}^{* *}+\left(1-\pi_{E}\right) c_{L}^{* *}$.
} 
(i) If $1 / u^{\prime}$ is convex and $u^{\prime \prime \prime}>0, c_{0}^{* *}<c_{0}^{*}$ (non-exclusivity reduces borrowing).

(ii) $c_{H}^{* *}-c_{L}^{* *}>c_{H}^{*}-c_{L}^{*}$ and $c_{H}^{* *}>c_{H}^{*}$ (non-exclusivity reduces insurance).

It is not true for general utility functions that the optimal contract when the secondary credit market is operating involves reduced borrowing, however. For instance, with quadratic preferences (no precautionary savings) a similar argument as the one in the proof of Proposition 3 shows that the optimal contract with a secondary credit market involves higher borrowing. For the special case of logarithmic utility Proposition 3 obviously implies that $c_{0}^{* *}<c_{0}^{*}$. Moreover, in this case we have a sharper characterization of the insurance effect, namely $\frac{c_{H}^{* *}}{c_{L}^{* *}}>\frac{c_{H}^{*}}{c_{L}^{*}}$.

It is also of interest to characterize the equilibrium deviation of the entrepreneur at the optimal contract. In other words, if the entrepreneur would actively trade in the secondary credit market (remember that in equilibrium the entrepreneur is indifferent between trading and not trading in such markets), which contract would he trade? Would such a contract involve borrowing or lending by the entrepreneur?

More precisely, given the optimal contract offered by the bank in equilibrium, $\left(I^{* *}, B_{H}^{* *}, B_{L}^{* *}\right)$, the equilibrium deviation of the entrepreneur is the solution to the following maximization problem:

$\max _{\gamma, R_{H}, R_{L}} u\left(\alpha+I^{* *}+\gamma-1\right)+\pi_{e} u\left(\omega_{H}-B_{H}^{* *}-R_{H}\right)+\left(1-\pi_{e}\right) u\left(\omega_{L}-B_{L}^{* *}-R_{L}\right)-v(e)$,

subject to (7). Thus, the equilibrium deviation is the choice of $\left(\gamma, R_{H}, R_{L}\right)$ at which the incentive constraint holds with equality.

Proposition 4 Suppose Assumptions 1-3 hold, contractual relationships are nonexclusive, there is no bankruptcy institution and $u^{\prime}$ is concave or not too convex. Then at the equilibrium deviation the entrepreneur would lend to the secondary market, i.e., $\gamma<0$.

A similar result, namely that an agent would like to save at the optimal contract given the chance to do so, holds for economies in which the bank can enforce exclusive contracts, a direct implication of Proposition 1 (see Rogerson (1985)). In the literature this implication of principal agent models of borrowing and lending markets is generally considered counterintuitive, since banks seem to be mostly concerned with the possibility of debtors incurring excessive unobserved liabilities in secondary markets, rather than with the possibility of unobserved saving. We will show in the next subsection that this result is reversed when we allow for bankruptcy, since in that case the entrepreneur at the optimal contract would consider borrowing in secondary markets. 


\subsection{Non-exclusive Contracts and Bankruptcy}

We now consider the case in which there exists a secondary market which can provide the entrepreneur with credit in addition to what is already provided by the bank, and in which the entrepreneur is allowed to default on his debt obligations and declare bankruptcy. In case of bankruptcy, the entrepreneur receives a fixed, predetermined amount of consumption $P$. The bank enforces its claim on the entrepreneur's funds exceeding $P$ and hence the bank receives the difference between the output of the project, plus any positive payoffs of other claims that the entrepreneur might have and $P$, up to the full credit amount. The secondary lenders are partially reimbursed if and only if the bank is fully repaid.

We will show that the optimal contract offered by the bank induces the entrepreneur to declare bankruptcy in the low state and only in the low state. This implies that the entrepreneur will have no incentive to save for state $L$ using secondary markets, because such savings would be seized by the bank and hence go towards repaying the bank. The entrepreneur will also not be able to borrow against the state $L$ in secondary markets, because he could not repay such secondary loans unless the bank had been repaid in full. Thus, the ability of the bank to enforce its claim on any funds that the entrepreneur has exceeding the bankruptcy protection level in bankruptcy reduces the entrepreneur's incentives to trade in secondary markets. This enables the bank to provide more insurance than in the absence of bankruptcy which improves the entrepreneur's utility under the optimal contract. Notice that the bankruptcy protection level $P$, which limits the liability of the entrepreneur, is endogenously determined as part of the optimal contract rather than an exogenous friction.

Importantly, we do not allow the level of bankruptcy protection $P$ to be state contingent. This restriction is necessary in our set-up to indirectly capture the costs of bankruptcy, since we do not introduce explicit costs associated with the bankruptcy procedure. If it were feasible and costless to make $P$ state contingent, the bank could enforce a specific consumption allocation for the entrepreneur for free in all states and the optimal exclusive contract could hence be implemented. We discuss this assumption in more detail in Section $4 .{ }^{21}$

As in the previous case we will transform the equilibrium analysis of the economy into the solution of a programming problem. The following preliminary analysis simplifies the statement of the problem. Recall that we want to show that at an equilibrium the bank's contract is set to induce the entrepreneur to

\footnotetext{
${ }^{21}$ We proceed as if the choice of $P$ is part of the contract offered by the bank. Implicitly, we are thus determining the optimal bankruptcy protection level. More generally we should think of the bankruptcy provisions as an ex ante ("political") choice encompassing many or, in fact, all contracts and taking borrower heterogeneity into account, but it makes no difference in the simple economy we consider here.
} 
choose the high effort $E$ and to declare bankruptcy in state $L$ only. Such a contract exists, since in the relevant range of contracts the bank can always set the notional repayment in state $L, B_{L}$, sufficiently high to ensure that the entrepreneur will be insolvent in that state, and only in that state, even after taking into account the possibility of the borrower trading in the secondary credit market.

The optimal contract offered by the bank and the equilibrium allocation in the economy with non-exclusive contractual relationships and no bankruptcy, derived in the previous subsection, are sustainable in the present environment with bankruptcy. It is sufficient to set the bankruptcy provision $P$ to 0 . Furthermore, this equilibrium allocation can be supported by a contract which induces bankruptcy in state $L$ by choosing the bankruptcy provisions appropriately. Such a contract, $\left(I, B_{H}, B_{L}, P\right)$, will specify a high enough notional repayment in state $L, B_{L}$, so that the entrepreneur will be insolvent, declare bankruptcy and consume $P$, which is set equal to the equilibrium allocation in state $L$ which we want to support, $c_{L}^{* *}$.

We still need to check that the set of contracts which can be offered to the entrepreneur in the secondary market is not enlarged as a consequence of the introduction of the bankruptcy institution, so that in equilibrium the secondary market will remain inactive. This could only happen if the entrepreneur were offered a contract which he would accept and which would induce him to change the pattern of bankruptcy declaration (for instance would induce him to declare bankruptcy in state $H$ and not in state $L$ ). The entrepreneur will declare bankruptcy in each state of the world $s \in\{H, L\}$ in which $\omega_{s}-B_{s}-R_{s}<P$. It is easy to see that, by controlling $B_{L}$, the bank can make it prohibitively costly for secondary markets to change the pattern of bankruptcy declaration without affecting the equilibrium allocation of the entrepreneur (who never in fact repays $B_{L}$ since he declares bankruptcy in state $\left.L\right)$.

The equilibrium allocation $\left(c_{0}^{* *}, c_{H}^{* *}, c_{L}^{* *}\right)$ implies utility $u^{* *}$ for the entrepreneur. Could the entrepreneur reach higher utility with contracts with a different bankruptcy declaration pattern? We argue that the answer is no. Consider the three possible alternative bankruptcy declaration patterns in turn:

First, suppose the entrepreneur goes bankrupt in both state $H$ and state $L$. Then he is fully insured, $c_{H}=c_{L}=P$, and chooses the low effort, $e$. As a consequence this contract is (weakly) dominated by the contract providing the entrepreneur with full insurance and perfect smoothing and the bank with nonnegative expected profits. But such a contract, under Assumptions 1-3, is in turn strictly dominated by the contract which implements utility $u^{* *}$, which we just showed is feasible and incentive compatible under bankruptcy in $L$.

Second, suppose the entrepreneur never goes bankrupt, neither in state $H$ nor in state $L$. Then, if the utility for the entrepreneur associated with this contract is at least $u^{* *}, P$ and $B_{L}$ can be chosen so that the entrepreneur is forced into 
bankruptcy in state $L$, while leaving his allocation and hence the utility associated with the contract unchanged.

Finally, suppose the entrepreneur goes bankrupt only in state $H$. In this case the consumption allocation in state $L$ must necessarily be greater than the bankruptcy provision (and hence the allocation in the bankruptcy state $H$ ): $c_{L} \geq P$. It follows that the entrepreneur can never be induced to choose the high effort $E$. Again all possible allocations are then dominated by the allocation guaranteeing utility $u^{* *}$, which is feasible and incentive compatible under bankruptcy in $L$.

We have therefore demonstrated that in equilibrium the entrepreneur will declare bankruptcy in state $L$ only. We can then restrict the set of contracts offered by the bank without loss of generality to those which induce bankruptcy only in state $L$. This implies that any contract offered by the secondary market will specify a zero repayment in state $L$. Since in bankruptcy any assets exceeding the bankruptcy protection $P$ will be assigned to the bank as repayment, the entrepreneur has no incentive to set $R_{L}$ negative. Similarly, since the entrepreneur goes bankrupt in state $L$, he will not honor liabilities with secondary lenders, and thus $R_{L}$ can not be positive.

More specifically, we can without loss of generality restrict the contract offered by the bank to one which satisfies

$$
\omega_{H}-B_{H}>P
$$

and $B_{L}$ sufficiently high, in particular,

$$
B_{L}>\omega_{L}-P
$$

and thus we can, again without loss of generality, restrict the contracts offered in the secondary market to satisfy:

$$
\begin{gathered}
R_{L}=0, \quad \pi_{e} R_{H} \geq \gamma \\
\omega_{H}-B_{H}-R_{H} \geq P .
\end{gathered}
$$

To specify the optimal contracting problem solved by the bank, therefore, we need to characterize the entrepreneur's utility associated with a deviation to effort $e$ and optimal trading in the secondary credit market for any contract offered by the bank. Given any contract offered by the bank, $\left(I, B_{H}, B_{L}, P\right)$, which satisfies properties (10-11), the utility that the entrepreneur can reach by optimally deviating, that is by choosing effort $e$ and trading in the secondary market, is

$$
u^{D}\left(I, B_{H}, B_{L}, P\right) \equiv \max _{R_{H}, \gamma} u(\alpha+I+\gamma-1)+\pi_{e} u\left(\omega_{H}-B_{H}-R_{H}\right)
$$




$$
+\left(1-\pi_{e}\right) u(P)-v(e)
$$

subject to

$$
\begin{gathered}
\pi_{e} R_{H} \geq \gamma \\
\omega_{H}-B_{H}-R_{H} \geq P^{22} .
\end{gathered}
$$

The optimal contracting problem can then be written as:

$$
\max _{I, B_{H}, B_{L}, P} u(\alpha+I-1)+\pi_{E} u\left(\omega_{H}-B_{H}\right)+\left(1-\pi_{E}\right) u(P)-v(E)
$$

subject to

$$
\pi_{E} B_{H}+\left(1-\pi_{E}\right)\left(\omega_{L}-P\right) \geq I
$$

and the incentive constraint:

$$
u(\alpha+I-1)+\pi_{E} u\left(\omega_{H}-B_{H}\right)+\left(1-\pi_{E}\right) u(P)-v(E) \geq u^{D}\left(I, B_{H}, B_{L}, P\right),
$$

where $u^{D}\left(I, B_{H}, B_{L}, P\right)$ is defined by the maximization problem (14).

We can now characterize the equilibrium allocation of the entrepreneur, the implied utility attained, the structure of the optimal contract offered by the bank, and the contract which constitutes the optimal deviation for the entrepreneur in the secondary credit market.

Let $u^{*}$ denote the utility associated with the equilibrium allocation of the economy with exclusive contracts and no bankruptcy institution, $u^{* *}$ denote the utility associated with the equilibrium allocation of the economy with non-exclusive contracts and no bankruptcy institution, and $u^{+}$the utility associated with the equilibrium allocation of the economy with non-exclusive contracts and a bankruptcy institution.

Proposition 5 Suppose Assumptions 1-3 hold. Then the entrepreneur prefers the optimal contract with non-exclusive contracts and bankruptcy to the optimal contract with non-exclusive contracts and no bankruptcy; but he prefers the optimal

\footnotetext{
${ }^{22}$ Notice that because we assume that secondary lenders share the proceeds in bankruptcy equally, we can ignore the strategic interaction among secondary lenders and proceed as if there is only one secondary lender. In fact, it is not possible for yet another lender to enter and offer an additional loan that induces bankruptcy, earns non-negative expected profits and makes the entrepreneur better off. The additional lender could only make the entrepreneur better off, while ensuring non-negative expected profits for himself, if he had an externality on the secondary lenders. But if $R_{H}<1 / 2\left(c_{H}-P\right)$, then the secondary lenders get fully repaid even if the borrower declares bankruptcy and thus there is no externality. But since the aggregate repayment $R_{H}$ can be implemented by loans from more than one lender, say $n$ lenders, and we can choose $n$ such that $R_{H}<n /(n+1)\left(c_{H}-P\right)$, it is possible to implement any aggregate repayment $R_{H}$ while avoiding externalities from additional lenders.
} 
contract with exclusive contracts and no bankruptcy to the optimal contract with a secondary credit market and bankruptcy:

$$
u^{* *}<u^{+}<u^{*}
$$

In the case in which there is a secondary credit market and exclusive contracts are not enforceable, the possibility of bankruptcy relaxes the incentive constraints. Bankruptcy allows the bank to ensure that the entrepreneur does no end up with funds exceeding a fixed amount $P$. The bank chooses a notional repayment in state $L$ which is sufficiently high that the entrepreneur will declare bankruptcy in that state. The entrepreneur has no incentive to enter into contracts with secondary lenders which pay off in the low state. Since he declares bankruptcy in that state, any such payoff which would give the entrepreneur a consumption level exceeding the bankruptcy protection $P$ would go towards repaying the bank. In addition, since the bank can ensure that the debt in the secondary credit market is not repaid unless the bank has been fully repaid, the secondary lenders would in fact not be repaid in that state. Thus, they would not lend to the entrepreneur against the promise of repayment in the low state. This restricts the set of contracts that the secondary lenders can offer while making non-negative expected profits to those that require repayment in state $H$. To sum up, bankruptcy in state $L$ implies that the entrepreneur has no incentive to save into state $L$ using the secondary market and can not borrow against state $L$ in secondary markets either. In this sense, the ability of the bank to enforce its claim on the borrower's funds in excess of the bankruptcy protection level in bankruptcy enables the bank to effectively enforce exclusivity in state $L$. Hence, the incentive constraints are relaxed and the optimal contract when bankruptcy is allowed for is preferred to the optimal contract when bankruptcy is not allowed for.

The institution of bankruptcy does not completely substitute for the enforceability of exclusive contracts. In particular, the entrepreneur can still borrow against and save into state $H$ using secondary markets. Thus, the repayment schedule of the loan from the bank must be such that the entrepreneur has no incentive to choose effort $e$ and supplement the contract offered by the bank with contracts offered by secondary lenders which require repayment in state $H$. This constrains the contracts offered by the bank relative to the contracts offered in the case in which there is no secondary credit market and exclusive contracts are enforceable.

We have analyzed the problem with bankruptcy under the assumption that secondary lenders share the proceeds in bankruptcy equally. It is important however to notice that our main result, namely Proposition 5, is independent of that assumption. Clearly, given that the institution of bankruptcy is welfare improving taking our assumption about the sharing rule as given, it would be welfare 
improving if we were allowed to choose the sharing rule in the secondary markets. But, no matter what the sharing rule, there cannot be an equilibrium in which the existence of the secondary markets does not impose any constraints on the set of contracts which can be offered by the bank. If the bank offers the optimal exclusive contract, it is never an equilibrium for the secondary market to be inactive. Thus, the exclusive contract cannot be implemented no matter what the sharing rule in the secondary market. How to design the optimal sharing rule in the secondary market is an interesting open question.

The characterization of the optimal contract can be summarized as follows: The optimal contract induces bankruptcy in state $L$ and only in state $L$ (as established above). Furthermore, denoting the optimal contract by $\left(I^{+}, B_{H}^{+}, B_{L}^{+}, P\right)$, the bank can choose the notional repayment $B_{L}^{+}$so that $B_{L}^{+}=B_{H}^{+}$. To see why, notice that by setting $B_{L}^{+} \geq B_{H}^{+}$the bank makes non-negative expected profits even if the entrepreneur does not declare bankruptcy in state $L$. Thus, the entrepreneur cannot profit from avoiding bankruptcy in state $L$. Setting $B_{L}^{+}$equal to $B_{H}^{+}$is hence sufficient. The point is that it is not necessary to set the notional repayment in the low state $B_{L}^{+}$higher than the repayment in the high state $B_{H}^{+}$, which would be unrealistic.

The possibility of bankruptcy, we argued, relaxes the incentive constraints. As a consequence, the optimal contract in this case provides more insurance to the entrepreneur. Furthermore, if $u^{\prime \prime \prime}>0$, the amount of the loan that the borrower gets from the bank under the optimal contract with bankruptcy exceeds the amount he gets if there is no bankruptcy institution.

Proposition 6 Suppose Assumptions 1-3 hold and assume that contractual relationships are non-exclusive. Then:

(i) If $u^{\prime \prime \prime}>0$, then $c_{0}^{+}>c_{0}^{* *}$.

(ii) $c_{H}^{* *}-c_{L}^{* *}>c_{H}^{+}-c_{L}^{+}$and $c_{H}^{* *}>c_{H}^{+}$.

The intuition is as follows: As argued in Section 3.2, when there is a secondary market but no bankruptcy institution, the bank reduces the amount of insurance provided to the entrepreneur to make it costly for him to trade in secondary markets. When there is a bankruptcy institution, the entrepreneur's trades in the secondary market are restricted as discussed above. Given these reduced incentives to trade in secondary markets, the bank provides more insurance and may lend more than in the absence of bankruptcy.

We now characterize the equilibrium deviation, that is the best possible contract which can be offered in equilibrium in the secondary market or, in other words, the solution to the maximization problem (14). 
Proposition 7 Suppose Assumptions 1-3 hold and assume that contractual relationships are non-exclusive. In the economy with bankruptcy, the equilibrium deviation of the entrepreneur in the secondary market satisfies $\gamma=\pi_{e} R_{H}>0$.

The proof is straightforward and is hence omitted. The entrepreneur thus considers taking out an additional loan in the secondary market. Again, this is in contrast to the standard result in the literature which implies that the agent would consider saving an extra amount. The intuition for our result is that since the debtor declares bankruptcy in the low state and additional assets are seized, there is no point in carrying extra resources into that state. The debtor is hence considering deviations involving time 0 and the high state at time 1 only. Given that, he is tempted to borrow more against the good state at time 1 . Thus, the optimal contract is designed to keep the borrower from incurring excessive liabilities rather than to keep the borrower from saving too much in secondary markets.

\section{Discussion}

Our modeling of credit markets and of the institution of bankruptcy is clearly simplified in several dimensions. In this section we discuss what appear to be our most restrictive assumptions and their implications as well as possible extensions of our analysis.

In our analysis the optimal design of the bankruptcy institution coincides with the optimal contract between the primary lender and the borrower. We would need to introduce heterogeneity of the borrowers and/or their projects in order to analyze the optimal contract independently from the bankruptcy institution. Notice that individual characteristics would affect the optimal bankruptcy protection level in our model. If such ex ante heterogeneity is not appropriately taken into account in bankruptcy law, the institution of bankruptcy may not be welfare improving and may in fact be welfare reducing at least for some borrowers.

We have abstracted from several important aspects of bankruptcy. For example, in our model there is no distinction between the borrower declaring bankruptcy and the lender putting the borrower into bankruptcy. In practice, there is a distinction in the law and it would be interesting to explain the rationale for the two provisions. Relatedly, bankruptcy laws in many countries allocate control rights to lenders when bankruptcy is declared. In our model, there is no inefficiency in leaving the project in the hands of the borrower and hence we interpret the allocation of control rights to the insider in Chapter 11 simply as a way to insure the insider. Clearly, if one were to add such an inefficiency to the model, this would provide a countervailing force and might explain the provisions which allocate control rights to the lenders. Notice however that as our model stands, lenders would not prefer more stringent bankruptcy provisions ex ante. 
We have assumed that contracts with secondary lenders are honored in bankruptcy. If we allowed for bankruptcy procedures which do not honor contracts in secondary markets, Pareto improvements in the equilibrium allocation may be possible. ${ }^{23}$ This is a consequence of our simplifying assumption that secondary credit has no intrinsic role in the economy. More generally, if secondary credit had a non-degenerate role in the economy, as for example in the case of trade credit, then our assumption that secondary credit contracts are honored in bankruptcy, as long as the bank has been repaid, would be more appropriate. Notice also that we study an environment in which exclusive contracts are optimal. In general, this may not be the case for example when there is an ex post holdup problem in an exclusive relationship as discussed in Sharpe (1990).

Relatedly, we have assumed that secondary lenders share the bankruptcy proceeds equally whenever they receive some reimbursement. In fact the sharing rule for secondary lenders should be considered a part of the design of the bankruptcy institution similar to the insurance provision $P$. Solving for the optimal sharing rule as part of the optimal contract between the bank and the borrower in our set-up would require an explicit analysis of the strategic interaction between secondary lenders - a daunting task. Our analysis is however robust to this extension insofar as the equilibrium allocation which can be achieved with non-exclusivity and bankruptcy, even allowing for the optimal choice of the sharing rule for secondary lenders, does not coincide with the equilibrium allocation which is achieved with exclusivity and no bankruptcy. This is true since in our set-up the allocation induced by exclusive contracts can be replicated only if bankruptcy is declared in state $L$ but not in state $H$. But if bankruptcy is declared only in state $L$, it is never an equilibrium for the secondary market to be inactive.

While our assumption about the sharing rule allows us to abstract from the strategic interaction of secondary lenders, which is important for tractability, this does not mean that we consider the coordination problem among multiple lenders unimportant in practice. Indeed, the role of bankruptcy in alleviating this coordination problem has been studied in the literature. ${ }^{24}$ Notice that in our environment, since there is only one lender in equilibrium, coordination problems among secondary lenders which constrain the secondary credit market would actually improve matters. It would however be an interesting extension to study an environment with multiple lenders in equilibrium in which bankruptcy alleviates exclusivity and coordination problems at the same time.

The focus of this paper is on the lack of enforceability of exclusivity ex ante, i.e., outside bankruptcy. In fact, in our model when bankruptcy is declared there

\footnotetext{
${ }^{23}$ But notice that this allocation would still be dominated by the optimal allocation with exclusivity and our main conclusion would be unaffected.

${ }^{24}$ See, e.g., Morris and Shin (2004). See also footnote 4.
} 
is no further contracting. In practice, borrowers often require and obtain additional financing after bankruptcy is declared, so called debtor-in-possession financing. Moreover, a number of debt covenants, including exclusivity covenants, lose enforceability with respect to further financing once the borrower declares bankruptcy. While we do not study this aspect of bankruptcy law, we think that the modeling approach provided here could be extended to address the effect of these provisions.

We have restricted the insurance provision in bankruptcy, $P$, to be state independent. As we noted earlier, this restriction is meant to capture the costs of bankruptcy. The restriction is crucial in our analysis since without it the bank would be able to enforce a specific consumption allocation for the entrepreneur in all states and the optimal exclusive contract could hence be implemented. This is solely due to the fact that we do not introduce explicit costs associated with the bankruptcy procedure. An economy in which bankruptcy is directly associated with the costly enforcement of exclusivity would however share most of the equilibrium properties with the economy studied here. Alternatively, the stateindependence of $P$ could be motivated by considering an economy in which the courts do not observe the realization of the state and hence can not enforce a level of bankruptcy protection contingent on it. Notice also that if there were more than two output realizations, our main results, namely that bankruptcy occurs when output is low, is welfare improving but not a perfect substitute for exclusivity and that borrowers are tempted to borrow more in secondary markets, would be unaffected, although the assumption that $P$ is state independent would be more restrictive in this case.

Finally, our result that bankruptcy is not a perfect substitute for exclusivity contrasts with the result derived by Bizer and DeMarzo (1999) in an interesting and closely related paper. They study the problem of a principal employing an agent who can borrow and lend as well as default on loans. They show that there is an optimal intermediate range of bankruptcy protection levels that attain constrained efficiency, i.e., the optimal exclusive allocation can be implemented when bankruptcy is allowed. Two important properties differentiate the environment studied by Bizer and DeMarzo (1999) from ours and are instrumental in generating their efficiency result. First, the cash flows from the project accrue to the principal and thus the transfer between the principal and the agent is a wage payment from the principal to the agent which is not affected by the bankruptcy procedure. In particular, the agent cannot default on the principal, but only on the "secondary" lenders. Second, only borrowing and lending contracts are considered in the secondary credit market and contracts that explicitly provide insurance are not allowed, which reduces the set of feasible deviations. 


\section{Conclusion}

We provide a rationale for the institution of bankruptcy. The institution of bankruptcy enables the enforcement of a primary lender's claim to any assets that the borrower has above the bankruptcy protection level. In the absence of enforceability of exclusive contracts ex ante there is a role for such an institution. Bankruptcy thus relaxes the constraints imposed by the lack of enforceability and alleviates the non-exclusivity problem. This means in particular that the borrower can not use secondary markets to insure himself against states in which he declares bankruptcy since the primary lender could claim such assets. Thus, a bankruptcy institution improves on non-exclusive contractual relationships by effectively enabling the primary lender to enforce a specific consumption allocation when bankruptcy is declared. However, the institution of bankruptcy is not a perfect substitute for exclusivity, that is, it is not equivalent to being able to enforce a specific consumption allocation in all states. At an abstract level, the paper studies a principal agent problem in which the agent can enter into "side contracts," but a primary contracting party can partially enforce its contract and seize payoffs of "side contracts" in some states of the world.

We characterize the implications for the optimal contract and the side contracts that an agent would consider. The institution of bankruptcy allows the agent to obtain a contract which provides him with more insurance and, under certain conditions, with a larger loan than in the absence of bankruptcy. Moreover, we show that in our model, in contrast to the standard result in the literature, the agent would consider taking out additional loans in secondary markets instead of saving.

The paper focuses on the role of bankruptcy in alleviating the non-exclusivity problem. In doing so, we have to abstract from several important issues affecting the determination of optimal bankruptcy law, such as borrower heterogeneity, the allocation of control rights, coordination problems, and the question of whether the borrower or the lender declares bankruptcy. It would be interesting to consider these aspects jointly with the non-exclusivity problem, but this is beyond the scope of this paper.

The paper proceeds formally as if the level of bankruptcy protection is part of the contract and hence the optimal contract in a sense determines the bankruptcy law. However, the essential difference between bankruptcy law and contractual default provisions is that the former applies to all contracts an agent enters into. This distinction becomes important when the contractual relationships of all parties in a contract are not observable. Indeed, the role which bankruptcy plays in our model is to limit the externalities across contracts when the subsequent contractual relationships of the parties in a contract are not otherwise observable. This might explain why bankruptcy law does not allow agents to "opt out." 


\section{Appendix}

Proof of Proposition 1. Note that Assumptions 2-3 guarantee that the set of $\left(I, B_{H}, B_{L}\right)$ which satisfy the set of constraints, equations (2-3), is non-empty. The constraint set is compact, the objective function continuous, and hence a solution exists. Letting $\mu$ and $\tau$ denote the Lagrange multiplier associated with equation (2) and (3), respectively, the necessary first order conditions of the problem are (2), (3) and

$$
\begin{gathered}
u^{\prime}(\alpha+I-1)=\mu \\
u^{\prime}\left(\omega_{H}-B_{H}\right)\left(1+\tau \frac{\pi_{E}-\pi_{e}}{\pi_{E}}\right)=\mu \\
u^{\prime}\left(\omega_{L}-B_{L}\right)\left(1-\tau \frac{\pi_{E}-\pi_{e}}{1-\pi_{E}}\right)=\mu .
\end{gathered}
$$

Since $u^{\prime}(c)$ is decreasing, by concavity of $u(c),(20-21)$ imply that $c_{H}>c_{L}$.

Simple algebraic manipulation of the first order conditions, (19-21), implies:

$$
\frac{1}{u^{\prime}\left(c_{0}\right)}=\pi_{E} \frac{1}{u^{\prime}\left(c_{H}\right)}+\left(1-\pi_{E}\right) \frac{1}{u^{\prime}\left(c_{L}\right)}
$$

Thus, expected consumption is decreasing if $1 / u^{\prime}$ is convex and increasing otherwise. The above equality also implies that $u^{\prime}\left(c_{0}\right)<\pi_{E} u^{\prime}\left(c_{H}\right)+\left(1-\pi_{E}\right) u^{\prime}\left(c_{L}\right)$.

Proof of Lemma 1. While (6) must hold for all $\left(\gamma, R_{H}, R_{L}\right)$ which satisfy (7), it is sufficient to impose it for $\left(\gamma, R_{H}, R_{L}\right)$ which solve:

$$
\max _{\gamma, R_{H}, R_{L}} u(\alpha+I+\gamma-1)+\pi_{e} u\left(\omega_{H}-B_{H}-R_{H}\right)+\left(1-\pi_{e}\right) u\left(\omega_{L}-B_{L}-R_{L}\right)
$$

subject to (7). It is easy to see that the argmaximum of this problem is reached at $\left(\gamma, R_{H}, R_{L}\right)$ which solve

$$
\begin{aligned}
c & \equiv \alpha+I+\gamma-1=\omega_{H}-B_{H}-R_{H}=\omega_{L}-B_{L}-R_{L} \\
& =\frac{1}{2}\left(\alpha+I-1+\pi_{e}\left(\omega_{H}-B_{H}\right)+\left(1-\pi_{e}\right)\left(\omega_{L}-B_{L}\right)\right)
\end{aligned}
$$

which proves part (i).

If $\left(I, B_{H}, B_{L}\right)$ satisfies $(8)$, then

$$
\begin{aligned}
& u(\alpha+I-1)+\pi_{E} u\left(\omega_{H}-B_{H}\right)+\left(1-\pi_{E}\right) u\left(\omega_{L}-B_{L}\right)-v(E) \\
\geq & 2 u\left(\frac{1}{2}\left(\alpha+I-1+\pi_{e}\left(\omega_{H}-B_{H}\right)+\left(1-\pi_{e}\right)\left(\omega_{L}-B_{L}\right)\right)\right)-v(e) \\
> & u(\alpha+I-1)+\pi_{e} u\left(\omega_{H}-B_{H}\right)+\left(1-\pi_{e}\right) u\left(\omega_{L}-B_{L}\right)-v(e)
\end{aligned}
$$


which means that $\left(I, B_{H}, B_{L}\right)$ satisfies (3). Notice that the last inequality is strict since $\omega_{H}-B_{H}>\omega_{L}-B_{L}$, and thus (6) is (strictly) more restrictive than (3).

Proof of Proposition 2. Let $\mu$ and $\tau$ denote the Lagrange multipliers associated with equation (5) and (8), respectively. The first order conditions of the maximization problem are (5), (8), (9) and

$$
\begin{gathered}
u^{\prime}(\alpha+I-1)=\tilde{\mu} \\
u^{\prime}\left(\omega_{H}-B_{H}\right)+u^{\prime}(c) \tilde{\tau} \frac{\pi_{E}-\pi_{e}}{\pi_{E}}=\tilde{\mu} \\
u^{\prime}\left(\omega_{L}-B_{L}\right)-u^{\prime}(c) \tilde{\tau} \frac{\pi_{E}-\pi_{e}}{1-\pi_{E}}=\tilde{\mu}
\end{gathered}
$$

where

$$
\tilde{\mu} \equiv \frac{\mu}{1+\tau}+\frac{\tau}{1+\tau} u^{\prime}(c)
$$

and $\tilde{\tau} \equiv \tau /(1+\tau)$. As a consequence, $u^{\prime}\left(\omega_{H}-B_{H}\right)<u^{\prime}(\alpha+I-1)<u^{\prime}\left(\omega_{L}-B_{L}\right)$, and hence $\omega_{H}-B_{H}>\alpha+I-1>\omega_{L}-B_{L}$. Also, simply manipulating the first order conditions:

$$
u^{\prime}(\alpha+I-1)=\pi_{E} u^{\prime}\left(\omega_{H}-B_{H}\right)+\left(1-\pi_{E}\right) u^{\prime}\left(\omega_{L}-B_{L}\right) .
$$

The statement on precautionary savings now simply follows from (26).

Proof of Proposition 3. Part (i): The present (expected) value of consumption, $c_{0}+\pi_{E} c_{H}+\left(1-\pi_{E}\right) c_{L}$, is constant across the two cases (with or without the secondary credit market operating). But, Proposition 1 (and Rogerson's (1985) result) imply that in the absence of a secondary credit market $c_{0}^{*} \geq \pi_{E} c_{H}^{*}+\left(1-\pi_{E}\right) c_{L}^{*}$. On the other hand, Proposition 2 implies that when there is a secondary credit market $c_{0}^{* *}<\pi_{E} c_{H}^{* *}+\left(1-\pi_{E}\right) c_{L}^{* *}$. The consumption at time $t=0$ must then be lower when there is a secondary credit market, and so is $I$.

Part (ii): The proof is in 3 steps. Step 1: We claim that $\left(c_{H}^{* *}, c_{L}^{* *}\right) \not \leq\left(c_{H}^{*}, c_{L}^{*}\right)$. Suppose instead that $\left(c_{H}^{* *}, c_{L}^{* *}\right) \leq\left(c_{H}^{*}, c_{L}^{*}\right)$ and hence $c_{0}^{* *} \geq c_{0}^{*}$ since the present value of both consumption allocations has to be the same. But then

$$
u^{\prime}\left(c_{0}^{*}\right) \geq u^{\prime}\left(c_{0}^{* *}\right)=\pi_{E} u^{\prime}\left(c_{H}^{* *}\right)+\left(1-\pi_{E}\right) u^{\prime}\left(c_{L}^{* *}\right) \geq \pi_{E} u^{\prime}\left(c_{H}^{*}\right)+\left(1-\pi_{E}\right) u^{\prime}\left(c_{L}^{*}\right),
$$

which contradicts Proposition 1. Step 2: In the case of no secondary credit market the incentive compatibility constraint is binding at an optimal solution and implies that

$$
u\left(c_{H}^{*}\right)-u\left(c_{L}^{*}\right)=\frac{v(E)-v(e)}{\pi_{E}-\pi_{e}} .
$$


When there is a secondary credit market, the incentive compatibility constraint evaluated at an optimal solution implies

$$
\begin{aligned}
& 1 / 2 u\left(c_{0}^{* *}\right)+\pi_{E} / 2 u\left(c_{H}^{* *}\right)+\left(1-\pi_{E}\right) / 2 u\left(c_{L}^{* *}\right)-1 / 2 v(E) \\
\geq & u\left(1 / 2 c_{0}^{* *}+\pi_{e} / 2 c_{H}^{* *}+\left(1-\pi_{e}\right) / 2 c_{L}^{* *}\right)-1 / 2 v(e) \\
> & 1 / 2 u\left(c_{0}^{* *}\right)+\pi_{e} / 2 u\left(c_{H}^{* *}\right)+\left(1-\pi_{e}\right) / 2 u\left(c_{L}^{* *}\right)-1 / 2 v(e)
\end{aligned}
$$

and thus

$$
u\left(c_{H}^{* *}\right)-u\left(c_{L}^{* *}\right)>\frac{v(E)-v(e)}{\pi_{E}-\pi_{e}}=u\left(c_{H}^{*}\right)-u\left(c_{L}^{*}\right) .
$$

Now suppose that $c_{H}^{* *} \leq c_{H}^{*}$ and thus $c_{L}^{* *} \geq c_{L}^{*}$ by step 1 . This contradicts equation (27) and hence $c_{H}^{* *}>c_{H}^{*}$, i.e., the second assertion of part (ii) is established. Step 3: $c_{H}^{* *}>c_{H}^{*}$ together with equation (27) imply the first assertion.

Proof of Proposition 4. Since the entrepreneur would fully insure and perfectly smooth, $\gamma=1 / 2\left(\pi_{e} c_{H}^{* *}+\left(1-\pi_{e}\right) c_{L}^{* *}-c_{0}^{* *}\right)$. If $u^{\prime}$ is concave, $c_{0}^{* *}>\pi_{E} c_{H}^{* *}+$ $\left(1-\pi_{E}\right) c_{L}^{* *}>\pi_{e} c_{H}^{* *}+\left(1-\pi_{e}\right) c_{L}^{* *}$ and thus $\gamma<0$. As long as $u^{\prime}$ is not too convex, $u^{\prime}\left(c_{0}^{* *}\right)<\pi_{e} u^{\prime}\left(c_{H}^{* *}\right)+\left(1-\pi_{e}\right) u^{\prime}\left(c_{L}^{* *}\right)$ will imply that $u^{\prime}\left(c_{0}^{* *}\right)<u^{\prime}\left(\pi_{e} c_{H}^{* *}+\left(1-\pi_{e}\right) c_{L}^{* *}\right)$, i.e., $c_{0}^{* *}>\pi_{e} c_{H}^{* *}+\left(1-\pi_{e}\right) c_{L}^{* *}$ and $\gamma<0$.

Proof of Proposition 5. To show that $u^{+}<u^{*}$ it suffices to show that

$$
\frac{\partial\left(u\left(c_{0}^{*}+\gamma\right)+\pi_{e} u\left(c_{H}^{*}-\frac{\gamma}{\pi_{e}}\right)+\left(1-\pi_{e}\right) u\left(c_{L}^{*}\right)\right)}{\partial \gamma}>0,
$$

at $\gamma=0$, which is straightforward to check.

To see that $u^{+}>u^{* *}$, notice that since $\left(c_{0}^{* *}, c_{H}^{* *}, c_{L}^{* *}\right)$ satisfies the incentive compatibility constraint with non-exclusive contracts and no bankruptcy we have:

$$
\begin{aligned}
& u\left(c_{0}^{* *}\right)+\pi_{E} u\left(c_{H}^{* *}\right)+\left(1-\pi_{E}\right) u\left(c_{L}^{* *}\right)-v(E) \\
= & 2 u\left(1 / 2 c_{0}^{* *}+\pi_{e} / 2 c_{H}^{* *}+\left(1-\pi_{e}\right) / 2 c_{L}^{* *}\right)-v(e) \\
> & \left(1+\pi_{e}\right) u\left(1 /\left(1+\pi_{e}\right) c_{0}^{* *}+\pi_{e} /\left(1+\pi_{e}\right) c_{H}^{* *}\right)+\left(1-\pi_{e}\right) u\left(c_{L}^{* *}\right)-v(e),
\end{aligned}
$$

and thus $\left(c_{0}^{* *}, c_{H}^{* *}, c_{L}^{* *}\right)$ is incentive compatible with non-exclusivity and bankruptcy by setting $P=c_{L}^{* *}, B_{L}>\omega_{L}-P$ and such that $\pi_{e} B_{H}+\left(1-\pi_{e}\right) B_{L} \geq I$, and $B_{H}$ and $B_{L}$ supporting $c_{0}^{* *}, c_{H}^{* *}$, respectively. Since $c_{L}^{* *}<c_{0}^{* *}<c_{H}^{* *}$ (see the Proof of Proposition 2), the last inequality is strict and thus there exists a feasible and incentive compatible allocation with non-exclusive contracts and bankruptcy that improves the objective.

Proof of Proposition 6. We will first prove part (ii) and then part (i) of the proposition. 
Part (ii): Ignoring the constraint that $\omega_{H}-B_{H}-R_{H} \geq P$ for now, we have the following explicit expression for $u^{D}$ :

$$
\begin{aligned}
u^{D}\left(I, B_{H}, B_{L}, P\right) & =\left(1+\pi_{e}\right) u\left(\frac{1}{1+\pi_{e}}(\alpha+I-1)+\frac{\pi_{e}}{1+\pi_{e}}\left(\omega_{H}-B_{H}\right)\right) \\
& +\left(1-\pi_{e}\right) u(P)-v(e) .
\end{aligned}
$$

The first order conditions for the problem with bankruptcy are thus:

$$
\begin{aligned}
(1+\tau) u^{\prime}(\alpha+I-1) & =\mu+\tau u^{\prime}(c) \\
(1+\tau) u^{\prime}\left(\omega_{H}-B_{H}\right) & =\mu+\tau \frac{\pi_{e}}{\pi_{E}} u^{\prime}(c) \\
(1+\tau) u^{\prime}(P) & =\mu+\tau \frac{1-\pi_{e}}{1-\pi_{E}} u^{\prime}(P)
\end{aligned}
$$

where $c=1 /\left(1+\pi_{e}\right)(\alpha+I-1)+\pi_{e} /\left(1+\pi_{e}\right)\left(\omega_{H}-B_{H}\right)$ and $\mu$ and $\tau$ are the multipliers on the constraints. Clearly, $u^{\prime}\left(\omega_{H}-B_{H}\right)<u^{\prime}(\alpha+I-1)$ and thus $u^{\prime}(c)<u^{\prime}(\alpha+I-1)$. Hence, $u^{\prime}(\alpha+I-1)<(1+\tau) u^{\prime}(\alpha+I-1)-\tau u^{\prime}(c)=\mu$. But then the last first order condition implies that $u^{\prime}(P)>\mu$ and thus $c_{H}^{+}>c_{0}^{+}>c_{L}^{+}$. Setting $u^{\prime}(\alpha+I-1)$ equal to a weighted sum of the second two first order conditions shows that

$$
u^{\prime}\left(c_{0}^{+}\right)<\pi_{E} u^{\prime}\left(c_{H}^{+}\right)+\left(1-\pi_{E}\right) u^{\prime}\left(c_{L}^{+}\right) .
$$

An argument analogous to the one in the first step of the proof of Proposition 3 establishes that $\left(c_{H}^{* *}, c_{L}^{* *}\right) \not \leq\left(c_{H}^{+}, c_{L}^{+}\right)$.

The incentive compatibility constraint of the problem with bankruptcy implies

$$
\begin{aligned}
& u\left(c_{0}^{+}\right)+\pi_{E} u\left(c_{H}^{+}\right)+\left(1-\pi_{E}\right) u\left(c_{L}^{+}\right)-v(E)= \\
& \left(1+\pi_{e}\right) u\left(1 /\left(1+\pi_{e}\right) c_{0}^{+}+\pi_{e} /\left(1+\pi_{e}\right) c_{H}^{+}\right)+\left(1-\pi_{e}\right) u\left(c_{L}^{+}\right)-v(e),
\end{aligned}
$$

and the incentive compatibility constraint of the problem without bankruptcy implies

$$
\begin{aligned}
& u\left(c_{0}^{* *}\right)+\pi_{E} u\left(c_{H}^{* *}\right)+\left(1-\pi_{E}\right) u\left(c_{L}^{* *}\right)-v(E)= \\
& 2 u\left(1 / 2 c_{0}^{* *}+\pi_{e} / 2 c_{H}^{* *}+\left(1-\pi_{e}\right) / 2 c_{L}^{* *}\right)-v(e) \\
> & \left(1+\pi_{e}\right) u\left(1 /\left(1+\pi_{e}\right) c_{0}^{* *}+\pi_{e} /\left(1+\pi_{e}\right) c_{H}^{* *}\right)+\left(1-\pi_{e}\right) u\left(c_{L}^{* *}\right)-v(e),
\end{aligned}
$$

and thus

$$
\begin{aligned}
& \left(1+\pi_{e}\right) u\left(1 /\left(1+\pi_{e}\right) c_{0}^{+}+\pi_{e} /\left(1+\pi_{e}\right) c_{H}^{+}\right)+\left(1-\pi_{e}\right) u\left(c_{L}^{+}\right)> \\
& \left(1+\pi_{e}\right) u\left(1 /\left(1+\pi_{e}\right) c_{0}^{* *}+\pi_{e} /\left(1+\pi_{e}\right) c_{H}^{* *}\right)+\left(1-\pi_{e}\right) u\left(c_{L}^{* *}\right) .
\end{aligned}
$$

Denote the present value of a consumption allocation given action $a$ by $P V_{a}$. Recall that $P V_{E}^{+}=P V_{E}^{* *}$. Note that $P V_{e}=P V_{E}-\left(\pi_{E}-\pi_{e}\right)\left(c_{H}-c_{L}\right)$. Suppose 
that, by contradiction, $c_{H}^{* *}-c_{L}^{* *} \leq c_{H}^{+}-c_{L}^{+}$and hence $P V_{e}^{* *} \geq P V_{e}^{+}$. Equation (28) then implies that

$$
1 /\left(1+\pi_{e}\right) c_{0}^{* *}+\pi_{e} /\left(1+\pi_{e}\right) c_{H}^{* *}>1 /\left(1+\pi_{e}\right) c_{0}^{+}+\pi_{e} /\left(1+\pi_{e}\right) c_{H}^{+}>c_{L}^{+}>c_{L}^{* *},
$$

since otherwise a lottery with lower expected value would never be preferred. But then $c_{H}^{* *}>c_{H}^{+}$, a contradiction.

Part (i): Recall that the present (expected) value of consumption conditional on the high effort is the same in the two cases and that $u^{\prime}\left(c_{0}^{* *}\right)=\pi_{E} u^{\prime}\left(c_{H}^{* *}\right)+(1-$ $\left.\pi_{E}\right) u^{\prime}\left(c_{L}^{* *}\right)$ and $u^{\prime}\left(c_{0}^{+}\right)<\pi_{E} u^{\prime}\left(c_{H}^{+}\right)+\left(1-\pi_{E}\right) u^{\prime}\left(c_{L}^{+}\right)$. If $u^{\prime \prime \prime}>0$, then $c_{0}^{* *}<\pi_{E} c_{H}^{* *}+$ $\left(1-\pi_{E}\right) c_{L}^{* *}$. Given part (ii) established above, $c_{H}^{* *}-c_{L}^{* *}>c_{H}^{+}-c_{L}^{+}$and $c_{H}^{* *}>c_{H}^{+}$. Suppose $c_{0}^{+}<c_{0}^{* *}$ and hence $c_{L}^{+}>c_{L}^{* *}$. Then $\pi_{E} c_{H}^{+}+\left(1-\pi_{E}\right) c_{L}^{+}>\pi_{E} c_{H}^{* *}+\left(1-\pi_{E}\right) c_{L}^{* *}$ and thus

$$
\begin{aligned}
u^{\prime}\left(c_{0}^{* *}\right) & =\pi_{E} u^{\prime}\left(c_{H}^{* *}\right)+\left(1-\pi_{E}\right) u^{\prime}\left(c_{L}^{* *}\right) \\
& >\pi_{E} u^{\prime}\left(c_{H}^{+}\right)+\left(1-\pi_{E}\right) u^{\prime}\left(c_{L}^{+}\right)>u^{\prime}\left(c_{0}^{+}\right) .
\end{aligned}
$$

But this implies $c_{0}^{+}>c_{0}^{* *}$, a contradiction. 


\section{References}

[1] Admati, A., P. Pfleiderer and J. Zechner (1994). "Large Shareholder Activism, Risk Sharing, and Financial Market Equilibrium." Journal of Political Economy 102, 1097-1130.

[2] Aghion, P., O. Hart and J. Moore (1992). "The Economics of Bankruptcy Reform." Journal of Law, Economics and Organization 8, 523-46.

[3] Allen, F. (1985). "Repeated Principal-agent Relationships with Lending and Borrowing." Economic Letters 17, 27-31.

[4] Arnott, R. and J. Stiglitz (1983). "Equilibrium in Competitive Insurance Markets with Moral Hazard." Working Paper.

[5] Baird, D. (1993). The Elements of Bankruptcy. Revised Edition. Foundation Press, New York.

[6] Bebchuk, L. (1988). "A New Approach to Corporate Reorganizations." Harvard Law Review 101, 775-804.

[7] Berglöf, E., G. Roland and E.-L. von Thadden (2003). "Optimal Debt Design and the Role of Bankruptcy." Working Paper, Université de Lausanne.

[8] Berkovitch, E. and R. Israel (1999). "Optimal Bankruptcy Laws across Different Economic Systems." Review of Financial Studies 12, 347-77.

[9] Berkovitch, E., R. Israel and J. Zender (1997). "Optimal Bankruptcy Law and Firm-specific Investments." European Economic Review 41, 487-97.

[10] Biais, B. and C. Gollier (1997). "Trade Credit and Credit Rationing." Review of Financial Studies 10, 903-37.

[11] Bisin, A. and D. Guaitoli (1998). "Moral Hazard and Non-exclusive Contracts." Forthcoming, RAND Journal of Economics.

[12] Bizer, D. and P. DeMarzo (1992). "Sequential Banking." Journal of Political Economy 100, 41-61.

[13] Bizer, D. and P. DeMarzo (1999). "Optimal Incentive Contracts when Agents can Save, Borrow, and Default." Journal of Financial Intermediation 8, 241269.

[14] Bolton, P. and D. Scharfstein (1996). "Optimal Debt Structure and the Number of Creditors." Journal of Political Economy 104, 1-25. 
[15] Cole, H. and N. Kocherlakota (2001). "Efficient Allocations with Hidden Income and Hidden Storage." Review of Economic Studies 68, 523-542.

[16] Cornelli, F. and L. Felli (1997). "Ex-ante Efficiency of Bankruptcy Procedures." European Economic Review 41, 475-85.

[17] Dewatripont, M. and E. Maskin (1995). "Credit and Efficiency in Centralized and Decentralized Economies." Review of Economic Studies 62, 541-555.

[18] Dewatripont, M. and J. Tirole (1994). "A Theory of Debt and Equity: Diversity of Securities and Manager-Shareholder Congruence." Quarterly Journal of Economics 109, 1027-54.

[19] Dubey, P., J. Geanakoplos, and M. Shubik (2003). "Default and Punishment in General Equilibrium." Working Paper, Yale University.

[20] Franks, J. and W. Torous (1989). "An Empirical Investigation of U.S. Firms in Reorganization." Journal of Finance 44, 747-70.

[21] Fudenberg, D., B. Holmström and P. Milgrom (1990). "Short Term Contracts and Long Term Agency Relationships." Journal of Economic Theory 51, 1-31.

[22] Hart, O., R. La Porta, F. Lopez-de-Silanes and J. Moore (1997). "A New Bankruptcy Procedure that Uses Multiple Auctions." European Economic Review 41, 461-73.

[23] Kahn, C. and D. Mookherjee (1998). "Competition and Incentives with Nonexclusive Contracts." RAND Journal of Economics 29, 443-65.

[24] Morris, S., and H. Shin (2004). "Coordination Risk and the Price of Debt." European Economic Review 48, 133-153.

[25] Park, In-Uck (2003). "Moral Hazard Contracting and Private Credit Markets." Forthcoming, Econometrica.

[26] Petersen, M. and R. Rajan (1997). "Trade Credit: Theories and Evidence." Review of Financial Studies 10, 661-91.

[27] Rogerson, W. (1985). "Repeated Moral Hazard." Econometrica 53, 69-76.

[28] Schwartz, A. (1989). "A Theory of Loan Priorities." Journal of Legal Studies $18,209-61$.

[29] Schwartz, A. (1997). "Contracting about Bankruptcy." Journal of Law, Economics, and Organization 13, 127-46. 
[30] Sharpe, S. (1990). "Asymmetric Information, Bank Lending, and Implicit Contracts: A Stylized Model of Customer Relationships." Journal of Finance 45, 1069-87.

[31] Winton, A. (1995). "Costly State Verification and Multiple Investors: The Role of Seniority." Review of Financial Studies 8, 91-123.

[32] Zame, W. (1993). "Efficiency and the Role of Default when Security Markets are Incomplete." American Economic Review 83, 1142-64. 